\title{
5 Meme Collectives and Preferred Truths in Assam
}

\author{
Sagorika Singha
}

\subsection{Introduction}

This chapter focuses on memes and their rising popularity in the geopolitical region of Assam. It explores that which gives local memes their agency; in short, how diverse social media groups use memes to propagate or build public opinion among a new emerging public of internet users. Of late, social media has become a popular news source globally, and this is also true for Assam. But on social media, the news does not merely spread in a straight forward manner via numerous posts. Paratexts accompany these posts. In this context, paratexts - a term derived from literature refers to the multitude of extraneous, ephemeral popular cultural by-products that populate our contemporary mediascape (Pesce \& Noto, 2016). Memes these days act as a popular form of such paratexts, and they help put a spin on a news story or event through their movement in the digital space. This chapter considers certain instances where memes surface as vehicles propagating discussion around the socio-cultural and political situation in the form of a local situation or an inside joke and what this, in turn, tells us about the manifestation of the social order that exists in the social media space in local territories.

\subsection{Memes as Digital Objects}

In order to critically discuss meme as a cultural artefact this chapter reads meme as a "digital object" and borrows from Yuk Hui's On the Existence of Digital Objects (Hui, 2012). In Hui's analysis, digital objects move beyond the realm of representation, hence he considers them to be material objects. Considering the materiality of digital objects helps us engage with the socio-economic systems that lead to their emergence. Borrowing from and extending Hui's methodology, this chapter maps out a framework to delve into local digital objects, and in doing so, reimagines cultural geography as an associated milieu wherein memes reveal mechanisms of local "truth-making." Digital objects are bereft of the definitive qualities of "objects." What happens then when people find themselves representatives of an era of digital objects - digital objects which serve as floating objects of communication drifting from one screen to another, shared by one user with another? In doing so, they form chains and networks of connections which involve not just the sharing of those objects but also the knowledge of the social order of each user. 
Memes are a ubiquitous form of popular culture digital objects such as jokes, rumours, videos and websites which are circulated from person to person via the internet. People's interaction with media and infrastructure reveals their relation to the world and their respective nation-state. In accepting this, there is also the potential to foresee that the effect of individuation of digital objects is not only experienced by users and "machine agents" but is equally affected by the geographies they inhabit (Simondon, 1980). While objects have been historically understood as tangible things, here digital objects, memes, emerge as intangible artefacts that link users through their circulation. Further, memes serve a dual presence; they allow users to leave a digital trace online (as an extension of the self) while indicating an offline world (which our real selves inhabit).

\subsubsection{Digital Objects and Generation of Social Knowledge}

There is a distinctive difference between digital objects and their physical counterparts, including cultural records. While the latter is rooted in "solid, self-evident nature," the former remains evasive (Kallinikos, 2010). The signatory attributes of digital objects are editability, interactivity, openness, and distributedness (ibid.). While all of this holds true for memes, they are often evasive, ambivalent, paradoxical - features which affect not only their creation but also their circulation and meaning-making. Throughout this chapter, we witness these attributes at work with one another. As digital objects and despite being embedded "in local cultures and power structures," memes have allowed for a change in the way users interact and, more importantly, in the way social knowledge is generated online (Shifman, 2014). Most of the time, these digital artefacts or objects or things and their creators are themselves oblivious of the limit to their potency. This narration is an exercise in understanding how digital objects and artefacts have a life of their own, and how they bring forth an experience which pervades and affects various aspects of our lives.

Gilbert Simondon's notion of individuation deliberates that the genesis of an individual (either an individual or a social group standing for an individual) is a continuous process within an "associated milieu." As digital objects go through the process of concretisation, there is a presumption of improvement. Web 3.0 is supposed to be more enlightening than Web 2.0; GIFs are better than still images, and so on. However, following Simondon's idea of individuation, the never-ending process of concretisation allows for numerous possibilities. What we conceive at a point in the upgrade is just one of those multiple possibilities. In this chapter, local memes reveal different stages of apprehension or individuation, and not all of them engage with the same purpose. Within a regional milieu, as these digital objects grow, one of their potent objectives is the generation of social knowledge within the geography where they circulate. The caveat is that the social knowledge generated is also reflective of the composition and the order of society. This is revealed by the contesting mode of 
after-effects that the circulation of the digital objects leads to. While these artefacts are supposed to take on physical forms, what happens is that the instances triggered by these artefacts start reflecting the features of the objects themselves, namely, being evasive and ambivalent. This vagueness appears in the emergent post-truth era, marked by a rampant increase in the circulation of fake news, particularly in economies such as India. This is a transformation on a massive scale with far-reaching effects in the ways people interact, form opinions, and consume media information, as well as their experience of the "real" world which they inhabit.

The most fundamental way in which mobile media has transformed the contemporary world is by altering our relationships in social spaces. By demonstrating the sharing and creation of specific memes on social media platforms, mainly Facebook and WhatsApp, this chapter highlights the role such contemporary social digital objects play in driving this transformation in Assam. Users often create popular memes in the region in local languages such as Assamese, Bodo and Sylheti, among others. Language becomes a means for self-assertion, which is also a marker of "localisation" and the establishment of "cultural individualism." This development affects the tensions between the peripheral region of Assam (in northeast India) and the larger nation-state. The circulation of these memes leads to the emergence of a new vocabulary to discuss offline socio-political situations within specific social media groups. Additionally, they play a part in constructing conversations and events catering to a cluster or social group. The central concern here is how memes emerge as a newfound language and can develop platforms through their creators and users, in turn, transforming, asserting, and establishing new emerging publics.

Scholars have always looked at the northeast region of India as a politically unstable state with a history of secessionist movements and unrest (Mitra, 1993; Baruah, 2005; Bhaumik, 2009; Gill, 2013). However, there has been no significant attempt to read the region post the digital inroads, which have led to overwhelming changes. Propaganda and other pursuits go hand in hand with increased mobile internet penetration, and access to the internet ensures a new kind of landscape which no one has tried to gauge from a cultural study perspective. How are local citizens dealing with these changes and how are they affecting not only their appraisal of things and popular culture around them but also the production of these digital objects? Often, we find an incoherence in dealing with it. For example, on 18 May 2017, the Assam government issued an order announcing stricter monitoring of the use of social media (PTI, 2017). This order came after a series of unsavoury incidents ${ }^{10}$ concerning government officials went viral. In this context, a decision like this does

10 A slew of such incidents included the leak of a video showing MLA Ramakanta Deuri in a compromising position with an unidentified women in a hotel room (The Asian Age, 2017). In another incident, MLA Aminul Islam broadcast his Assembly speech through Facebook Live (Roy, 2017). 
not come as a surprise. It reflects poorly on the inability of both the users and the authorities to understand and control the online space.

Rumourmongering-instigated episodes and incidents riddle the current news landscape of the state, often accelerated by the use of memes on social media. In March 2017, there was a case of a Fatwa (that never was) issued against the popular reality show runners-up from Assam, Nahid Afrin (Saikia, 2017). The only evidence of any Fatwa was a leaflet signed by 46 clerics requesting residents not to attend musical performances or magic shows since they were against the Sharia. ${ }^{11}$ But the photo of the leaflet, written in the local Assamese language was shared extensively on social media and the non-existent threat on the life of the young singer was considered so real that the news received prime-time national TV and print media coverage (Saikia, 2017). As Sergio Sismondo remarks, "If the post-truth era starts by blowing up current knowledge structures, then it isn't very likely to be democratisation, and in fact most likely leads to authoritarianism" (Sismondo, 2018). There is a certain pattern to such propagations, as could be witnessed in the two cases mentioned above and many others which have cropped up in the past year in India. Most such incidents have taken place in tier II and III cities. ${ }^{12}$

There has been a definite shift in the way users access, interpret and consume information. The socio-economic and cultural milieu, along with users' interactions and adoption of the new technological dimension of information consumption affect this process. While the influence of social media and the behaviour of the youth has been chronicled (Tripathi, 2017; Arora \& Rangaswamy, 2015), there are gaps in analysing these phenomena from the perspective of the formation of the user units and exploring how social media changes the interpretation of current events within a particular user unit. The primary question here is how the increasing presence of social media platforms affect users in realising their selves in the way social media stages an event within such cultural discourses. How does it, for instance, encourage their view of themselves as mediated users? In the online space, how does their participation affect the functioning of the social establishment? In Assam, political or institutional participation in the online space has been prominent, and employees of various government departments are encouraged to participate in WhatsApp groups

11 Sharia law is part of the Islamic religious tradition. It is derived from the religious precepts of Islam, particularly the Quran and the Hadith.

12 The Reserve Bank of India classifies cities based on their population. Tier II cities population (between 500,000 and 5 million) and category Z or tier III cities (population below 5 lakh). Police, when asked by journalists about the recent bout of mob lynching which took place in the country following rumours of child-lifters, mention how the places where such incidents took place had a high concentration of poor and illiterate people (Raina, 2019). Pamposh Raina, "New Media and Indian Elections 2019” (The Indian Express \& Jindal School of Journalism and Communication’s (JSJC) panel discussion, New Delhi March 29, 2019). 
informally. Such institutions often use these groups to disseminate news and circulars within those sets of official participants.

Poe's law, first articulated in online forums, states that without a clear intention from the author, some readers might accept "obvious, exaggerated, parody of extreme views" to be true (Poe, 2005). Memes and GIFs take on a different value because they not only bring forward potent conversations in a casual and accepted way but are susceptible to Poe's law. It becomes all the more true for users who are becoming accustomed to this form of news dissemination. Once the user-base acknowledges this reality, it will be easier to understand the implications of the social makeup and to interpret political events through social media in a specific regional geography. This will bring evidence to the interpretation of culture and society among a relatively new kind of user-base and a new kind of political geography. Studies similar to this can ultimately help us understand in an ethnographic sense how events and popular culture deviate from textbook understanding when new media percolates into everyday plebeian discourse. When a user circulates a video or a meme online, an "apolitical" creator or propagator may remain "oblivious" that the readers and the receivers will interpret it in their own way. There is a lack of an established hierarchy in the comprehension of such information.

\subsubsection{Public Opinion Formation and the Meme-Machine}

Meme production is a machine exercise as it encourages an endless process of mining memes for their relevance and popularity. Memes work because they exhibit the classic attributes of the contemporary digital age - they are short, visual in nature, attention-grabbing, and users can discard them easily. They are easy catalysts for events of all nature. With the widening of the internet's reach, the relevance of memes has been growing, making the potency of the artefacts more visible and impending. Memes and discussions surrounding them act as crucial opinion generators. There lie two facets in the "humour element" that is intrinsic to the form - which often features a text tag overlaid on an image - while it grants the meme its momentum, the humour of a meme can often dilute the gravitas of an event. ${ }^{13}$

The asset of a meme lies in the latent potential of funny photoshopped images. The image referent with its instant political quality and easy shareability makes it impossible to ignore. Through memes, we witness the birth of "portable politics" for instant consumption on social media. In Assam, popular memeable characters are often local celebrities or figures in local media and politics. Posts which seem to be all

13 In reference to this, it is interesting to think of how the Amul hoardings (which also get published in newspapers etc.) precede the idea of a meme in terms of the usage of image and text and allusions to prevailing news scene in the country. 
the rage mainly involve caustic reactions to socio-political and cultural scenarios. The sarcasm-fuelled conversations provoked by such content become noteworthy when viewed through a lens of the "meme-synthesis." In essence, these conversations become significant because they reflect that the crises of the place, the region, are always a popular rhetoric and it comes as a small wonder that such content has the characteristics of vitriolic conversations and "strong" opinions.

Bjarneskans and his colleagues postulate that people strive to join a circle of individuals who "share the joke" (Bjarneskans et al., 1999). While this results in the creation of a group, often the participants strive to share individual opinions and issues which conform to the group's preferences merely because it seems cool to belong to the trendy crowd sharing similar beliefs. With regards to internet addiction, Jonathan J Kandell observed how a psychological dependence to being online could result in anxiety when one feels disconnected, thereby leading to a fear of missing out (Kandell, 1998). In a rush to belong, to find ever-popular and powerful memes, a user can inadvertently present an unpopular opinion which might prosper owing to the general propensity to "follow the crowd" on social media. We can see this in the contagious sharing of opinion that follows on social media.

\subsection{Network Economy and the Meme}

"Sharing" is the exhortation of the present generation, not just sharing one's private life and politics but also tastes, skills and capabilities. As Limor Shifman clarifies, sharing in this age stands both for distribution and consumption (Shifman, 2014). Sharing is also a way to network because when you share (and share widely) you also forge a network which spreads further depending on the amount of effort a user puts into that sharing. Sanjeev Goyal describes a network as a collection of nodes and links between them - individuals, firms, countries, or even a collection of such entities (Goyal, 2007). He also focuses on how structures of relationships assisted by such networks shape or influence individual behaviour in both a social and economic context. This reading is in opposition to another network approach, the ActorNetwork Theory (ANT), which espouses a material semiotic method to understand networks (Latour, 2014). ANT focuses on the relational ties within a network - "the tracing of associations" (ibid.). With users sharing memes, naturally, the circulation occurs within specific networks of individuals, and most of the time we find groups affirming to a common interest in terms of acceptance of ideas and political voices in order to belong to the socially desirable networks.

Ryan Milner introduces the concept of "polyvocality," the possibility of a varied range of voices to be heard, which is enabled by memes and other digital objects (Milner, 2012). Even though as a concept it seems promising, in an economically weak state its probability is questionable. Even when the infrastructure is in place, it is not easy for the economically and socially marginalised to readily access information 
owing to illiteracy or a lack of basic familiarity with the technology. In such regions, a different form of digital literacy evolves. As late adopters, users often associate the internet with social media since they access the internet's possibilities only through social media and smartphones. Even though mainstream media still exists as the vital component of opinion formation, particularly in public discourse, new media and its tools, such as memes, exist to dent its influence, questioning and - in this case even trolling it. For a new range of viewers, old media has become superfluous; an unavoidable, non-functioning necessity. In contrast, new media is the alternative; the substitute that they desire and one that they can customise.

Shifman observes how, in spite of the trend of a specific meme form, "the common ideas and forms shared by many internet memes might tell us something about digital culture" (Shifman, 2014). Memes do not exist in isolation. The sharing of images, memes, statuses, reviews to release emotional sentiments, among others, all contribute towards building the network. She considers this phenomenon as emergent of a central cultural logic which goes beyond the "sharing economies" (ibid.). In economic parlance, there is a value attached to such network formation. We can observe this pattern of value-making explicitly in the phenomenon of virality and which we often use as the barometer for measuring the success of online shared content. As Manual Castells muses, the new technological regime also results in a new networked, interdependent economy which ideally should encourage greater productivity and efficiency and which, in turn and with the right conditions, gives rise to equally dramatic organisational and institutional changes (Stark \& Castells, 1997). However, memes, which distinctly rely on "networks of mediated cultural participation in their creation, circulation, and transformation," go beyond those organisational changes (Milner, 2012). Memes have the potential to work on social representations and public discourse owing to their informal engagement as an everyday pop-cultural artefact. Their propagation through personal social networks can simultaneously give birth to an alternate social voice, with both its advantages and disadvantages.

\subsubsection{Memes Experience and Existence: Offline Dynamics Acting on Memes}

TAM, a vaguely defined acronym standing for multiple terms such as Trolls and Memes, and Trolling Assamese Media among others, is a meme collective based in Guwahati, Assam. It started by targeting local Assamese media extensively, and they pointed out flaws in their shoddy reporting, factual incongruencies and grammatical errors. Ironically their own memes had typographical errors and were poorly written most of the time. There seemed to be a fascination with targeting individuals. Even when talking about the media, the target was usually a particular reporter, owners of specific 
news channels, activists and others. If Assamese journalist Hemen Rajbonshi ${ }^{14}$ was the most trolled person in their memes in the early period of the group's existence, he was later replaced by activist Akhil Gogoi. Every time they targeted someone, they garnered a group of users who shared the sentiment towards that person.

Furthermore, the group succeeded in creating an echo chamber of their own. The pop-cultural rehashing of the politico-cultural events via such groups links back to the question of trivialisation. However, it is this trivialisation that makes a post or a meme go viral, and we can consider that these meme groups curate such echo chambers based on their inherent politics and ideology. It further heightens the societal divide between those with access and those without. In an already contested terrain, access become the criteria for determining who is privileged and who is not.

\subsection{Akhil Gogoi, or How a Peasant Leader Became a Meme}

Memes certainly have a specific agenda and, not surprisingly, they thrive while promoting that agenda in their own informal ways. Nevertheless, the Facebook groups discussed in this chapter which create vernacular memes (hereon referred to as meme collectives) generally deny any overt support for a particular ideology or political preference. When questioned, they profess to stand for a more common community approach with the primary purpose of being humorous in dealing with everyday crises (Administrators, 2017). Treating social events through that prism, they have their agenda in place, and this is reflected clearly in the kind of memes they come up with. In this regard, there are numerous categories and subjects that such meme collectives seem to favour. Considering the scope and limits of this chapter, I am taking only one such category of meme as a case study - the category of memes featuring peasant activist Akhil Gogoi. Gogoi is one of the most in-demand memeable entities within this meme collective.

Akhil Gogoi memes are a special case because of what he is associated with and how the collectives exploit their understanding of his politics. Gogoi is a well-known peasant and Right To Information (RTI) activist in Assam, India. He is the president of the Krishak Mukti Sangram Samiti (KMSS) (Farmers’ Freedom Struggle Committee) and a vehement critic of the right-leaning Bharatiya Janata Party (Indian People's Party) that leads the government at the centre. His critics have attacked him for his vitriolic speeches against the government's decisions, particularly regarding the

14 In August 2015, Hemen Rajbongshi, a reporter with the local Assamese channel, Pratidin Time, aired a news capsule on "scantily clad women" in Guwahati and described them as a nuisance during summer time. He was referring to women who wore mini-skirts or any version of the skirts. The viewers harshly criticised the sexist reporting on social media resulting in the birth of the "I am so Assamese" memes. 
granting of citizenship to Hindu Bangladeshis. ${ }^{15}$ The state has also accused him of instigating people to take up weapons to attack the government's "malicious intent." Considering the impact of Gogoi's activism on Assamese society and politics, it is not surprising that he is a regular feature in newspaper articles. What is interesting, however, is how an agrarian peasant leader, far removed from social media, has become one of the most popular memes in the region. Gogoi has been a memefriendly target of the Troll Assamese Media group since their inception in 2015. There is a self-vigilante sense of justice in the tone used by the people behind such memes. However, their notional value is contested owing to the collective's general, overt “ethno-nationalistic” leanings.

In this particular instance, the meme collective dissolves the public persona of a well-known and respected activist with the active use of topical memes which present a very different version of Gogoi - the activist. This section outlines the role such contemporary forms of social digital objects play in driving a construction of the image of specifically targeted individuals in Assam. This chapter assessed this by observing the sharing and creation of memes on social media platforms such as Facebook. In this way, apart from recognising the spatial and virtual connections that appear within the meme-world, the segment also reveals the inherent potency thriving in digital cultural objects and how they are employed to construct "preferred truths" to a cluster of social groups.

The TAM collective has two administrators. Owing to the rampant online threats they received, they asked to remain anonymous (Administrators, 2017). Both of them claim to work in print media but lack any formal training in the field. The convergence of print media and online media which led to the evolution of the collective could also highlight the patterns of access in the state itself. Even though internet access (primarily through mobile data) has increased, it is yet to replace print or other traditional media. When I asked one of the administrators what led him to create the group on Facebook, he replied, "During th(e) time Assamese media started yellow journalism. First, we started by trolling media, and then we trolled issues based on news. We have done it like a (sic) dynamism - to awaken people. To spread awareness among commonality (sic)" (Administrators, 2017). Their rationale for choosing Facebook as the platform and memes as the medium was that "Facebook is for common people and memes can attract (sic) easily in an attractive way ... there was no such meme page in Assam then" (ibid.). What caught my attention, though, was the passionate tone they used to explain their objective behind founding the group

15 In the 2014 General Election, the BJP government promised to amend the Citizenship Act, 1955 and introduced the Citizenship Amendment Bill of 2016 which will make illegal Hindus, Sikhs, Buddhists, Jains, Parsis and Christians migrants from Afghanistan, Bangladesh and Pakistan eligible for citizenship. 
which was to tackle what they perceived as the misuse of journalism in victimising people in a prejudicial manner.

From the example of the rise of the anti-Gogoi memes, what we can realise is that the activities of such meme collectives are disturbing, especially considering their trolling agenda. Their agenda seems innocuous and fun, but it is their political underpinnings that actually drive the conversations. In the case of this group in particular, the issues they project have a strong "Assamese identity, neglected state" sentiment to it. They discuss the poor infrastructure in the state, parental pressure, joblessness and unemployment and the underdeveloped media industry in general; they vocally display their united hatred against Bangladeshis and their shared love for Zubeen Garg ${ }^{16}$ and sports. All of these issues magnify the united identity of the "typical" Assamese youth and also vouch for a right-wing inspired political ideology. While the TAM collective refrains from claiming any political affiliation as such, they have no qualms in attacking others because of their political affiliations. Meanwhile, the popularity of the Akhil Gogoi memes which gradually grew to become a genre of their own in the meme collective's page reflects the value attached to what Gogoibashing stands for and how it is successful as a perspective.

The increasing attacks on him in real life reflect the infamy of Akhil Gogoi on the page. For those witnessing this phenomenon, the alarming question is whether one is affecting the other or is it because Gogoi ceases to be of interest in real politics that he becomes a staple on the online group's page. Talking to the young people in the group, it is interesting how the anarchism otherwise attributed to Gogoi become tepid in comparison to the hatred they shower on him. Memes often appropriate dominant discourse. However, Gogoi's support base, which lies among the liberal demography, draws a contradictory picture lauding him as "Assam's new voice of dissent" (Barbora, 2019). Diversity in any form of artefact circulation is important. However, when the means to create memes is accessible only to a specific group of people, the lack of diversity becomes troubling. It is a reminder of what Milner writes: that in the competition of meme creation, even though there is scope for a variety of perspectives to participate, it is only certain perspectives, values and references which gain ground (Milner, 2012). Here the digital transformation has occurred at a fast pace. However, users have difficulty coping with these transformations since the development in access is incongruous to their literacy and economic growth. Meanwhile, the creators of these online collectives have access to more resources and knowledge, allowing them to direct the conversation in the way they want because the majority of the consumers would not have the same agency and would be inclined to accept the creator's version as truth.

16 Zubeen Garg is a popular music artist from Assam. Garg is one of the most influential contemporary representatives of Assamese culture and identity. 


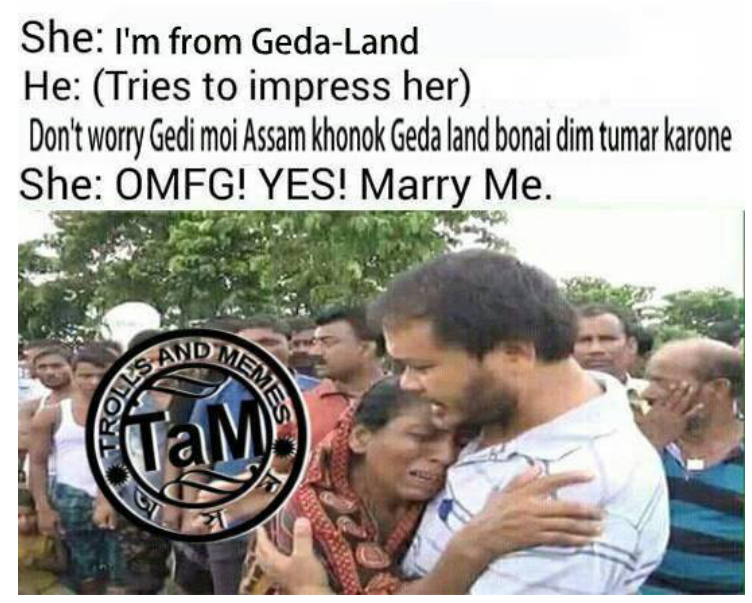

Figure 5.1: Akhil Gogoi Meme.

The original image in the meme (see figure 5.1) appeared for the first and only time on Twitter when Goutam Baruah, a self-proclaimed Sanatan Hindu, posted it in September 2016 right after the Kaziranga eviction incident. In his tweet he writes “\#Kaziranga Eviction Thnx AKHIL GOGOI 4 Uniting Assamese Ppl redardless (sic) of Political Differences..Great Job Assam Govt” (sic) (Baruah, 2016). The TAM meme collective rehashed the context of the image and used it numerous times on their page to propagate Gogoi's support for the illegal Bangladeshis. A sexual, more intimate pretext is used to underline the image as a visible form of the meme. Two other memes also establish a similar viewpoint of Gogoi demonstrating a deep, even sexual, attraction towards Bangladeshi immigrants. According to Milner, "Memes were a means to transform established cultural texts into new ones, to negotiate the worth of diverse identities, and to engage in unconventional arguments about public policy and current events. Memes were a mix of old inequalities and new participation" (Milner, 2012). Others though, including Liesbet van Zoonen, have questioned this position. Van Zoonen outlines how powerful institutions use populist forms of public discourse to influence the public (Van Zoonen, 2006). With cases such as these, we observe how emerging alternative media can also be used by individuals and groups to manipulate people into spreading their preferred view of the world.

Geert Lovink points out that since most memes spread within specific bubbles of people who share a viewpoint, the primary challenge lies in creating "bubblebreaking memes" (Lovink, 2017). Lovink rightly observes the method of using memes as a weapon, something exhibited in the US with the alt-right. According to him, 
memes are weaponised "as in shitposting ${ }^{17}$ on Twitter, a form of cognitive denial-ofservice attack." As he concludes, this sense of thematic identification is something that glues the sharers of the memes together. The localisation of memes, thus, inertly hints at the transformation of an original form, but a form which is nevertheless malleable. Thus, we can assume societies favouring certain memes also believe in their transformative potential. For example, sharing memes about consistent power cuts in the region can perhaps help when they reach the right officials who can improve the existing conditions so that the jokes about the problem no longer exist. Alternatively, vilifying and belittling a peasant activist and his stances can ultimately make him redundant and unnecessary in the eyes of the public. In a way, we can interpret this as the users' attempt to focus on issues which they imagine will improve when they are repeatedly discussed or pointed out on social media.

\subsubsection{The Media Event and the Meme}

Does a meme function as an event itself? In May 2017, following a series of WhatsApp circulated rumours, three men were lynched in Jharkhand's Singbhum district on suspicion of being child abductors (Special Correspondent, 2017). In Assam too, there have been numerous similar reports where information shared via social media was used to trigger incidents, including one identical to the Jharkhand incident (Karmakar, 2018; Anon., 2018; Anon., 2017). It is thus imperative to assess the effectiveness with which memes may trigger events by taking up a fake issue or news and plastering it over related images.

Moreover, its viral circulation makes its all the more probable for an event to become bigger in scope and consequently reach a larger group of people. Even though social media seems like a popular means to instigate or further prioritise a current issue, holding memes single-handedly responsible for creating an event will be too farfetched. Memes, though, act as indicators that gauge the importance of a current issue. In the case of the Akhil Gogoi trolling, one can see it as propaganda; an emotional, political issue is taken up and even mocked and associated with an assortment of other agendas, to make the memes surface repeatedly. When trolling him with that dose of humour and sarcasm, the desire is not only to make the collective hatred escalate but also to make it palatable and far-reaching.

Just like memes, we can also study how a personal form of exchange can be made responsible for a media event which is more public and widespread. It can thus be seen as an atomic response accumulating to form an event. So, can a meme be simply an agent of a media event and without the potential to be an event itself? To what

17 Shitpost is the internet slang for a worthless post on a message board, newsgroup, or other online discussion platform. 
extent is a meme central to the mobilisation of issues? If designed and received in the right way, a meme has immense potential to provide required value to a cause. The importance of the event does not have to be grand or its scale large. It can be local, or niche and its potency has to do with the impact it has - sometimes even at an individual level in the real world as witnessed by the lynchings instigated by WhatsApp rumours.

While a meme's potential is difficult to fathom, and it is questionable whether one meme alone can have a significant effect - sometimes its potential depends on the ambition of its creator and the user-base. There is every possibility of players misusing memes to a great extent, so we need to organise the meaning of the event itself if we want to understand the meme as a media event. Currently, with the examples at hand, a meme and its function are quite medium-specific. In other words, it transforms into something depending on the desires of its sharer and user-base. To the rumourmonger it is a vicious tool, to the exasperated armchair activist it is a cathartic rejoinder, to the humour-loving general public it is more of alternative entertainment and a valid way to contemporise their recreational media. Memes thus fall into the strange category of malleable objects, just like their malleable selves - photoshopped countless times, in numerous languages, the same image and the context may stand for one idea but might be loaned to many.

\subsection{Conclusion}

This chapter discusses the potency of apparently mundane digital artefacts to come together to reveal newer ways of expression and to emerge as the driving force behind such participation. We can conclude that the ingrained socio-political notions of online users steer obsessively popular meme topics and issues that ultimately ended up as inconsequential material for consumption by online users. Through meme collectives, the youth have found ways and means of fuelling old sentiments in a new garb. In many other instances (not discussed in this particular chapter), memes have highlighted burning issues in a way which makes them comprehensible and far more accessible to a new user-base. In the process, it is also evident that contemporary civil issues are morphed into their corresponding digital counterparts to suit current times. However, while it acts as a critical stance to whatever seems to be the problem at hand, it is also disturbing when the reins only seem to be available to a select few and issues can be equally subsumed as made prominent. The chapter contemplated how new media technologies bring change in the way small towns communicate, particularly in the way in which they discuss crises. While the traditional way of participation gets gradually but invariably transformed, particularly in the methods chosen for communicating ideas and events, it is clear that only particular sentiments and ideologies spread through these newer platforms. The creation of these platforms 
helped in building a cultural autonomy for the people of the region and also allowed for other controversial stances to exist and breed.

The growth of a new digital userbase participating, collaborating and building a sense of presence allowed for peripheral voices to thrive through their own energy. However, this occurred simultaneously with the proliferation of preferential views and the ease in creating factions and in circulating them. Those with keyboards at their fingertips had more say in this emergence. In this gradual transformation of the socio-cultural space in Assam, memes exist as a potent pursuer, as an easy catalyst extending the new media platform and encouraging the development of a contemporary local vocabulary which is aspirational but also has a succinct personality. While we cannot necessarily call memes tools of resistance, users do employ them as an effective intervention, and on the global stage they present a window for the local meme collectives' agenda-setting capabilities.

\section{References}

Administrators, T. (2017). Facebook Messenger [Interview] (25 October 2017),

Anon. (2017). BBC News. [Online] Retrieved March, 8, 2018 from https://www.bbc.com/news/ world-asia-india-39769172

Anon. (2018). News18.com. [Online] Retrieved July, 10, 2018 from https://www.news18.com/videos/ india/mob-beats-up-purported-holy-men-in-assam-1676687.html

Arora, P. \& Rangaswamy, N. (2015). Digital romance in the Indian city. Journal of Communication, 49(3), 84-105.

Barbora, S. (2019). Assam 's New Voice of Dissent. Economic and Political Weekly, 46(28), 19-22.

Baruah, G. (2016). Tweet. Guwahati: Twitter.

Baruah, S. (2005). India and its Northeast: A new politics of race. IIC Quarterly, 32(2 \& 3), pp. 165-76.

Baruah, S. (2010). Society versus State in Assam. In Durable Disorder: Understanding the Politics of Northeast India (pp. 123-144). New York: Oxford University Press.

Bhaumik, S. (2009). Troubled Periphery: Crisis of India's Northeast. New Delhi: Sage Publication. Bjarneskans, H., Grønnevik, B., \& Sandberg, A. (1999). The Lifecycle of Memes. [Online] Retrieved September, 23, 2018 from http://www.aleph.se/Trans/Cultural/Memetics/memecycle.html

Gill, P. (Ed.). (2013). The Peripheral Centre: Voices from India's Northeast. New Delhi(Delhi): Zubaan.

Goyal, S. (2007). Connections: An Introduction to the Economics of Networks. Princeton: Princeton University Press.

Hui, Y. (2012). What is a Digital Object?, Metaphilosophy, 43(4), 380-395. doi: 10.1111/j.14679973.2012.01761.x.

Kallinikos, J. (2010). Digital objects: Definitions and attributes, First Monday, 15(6), 1-16.

Kandell, J. J. (1998). Internet Addiction on Campus: The Vulnerability of College Students', CyberPsychology \& Behavior, 1(1), 11-17. doi: 10.1089/cpb.1998.1.11.

Karmakar, R. (2018). The Hindu. [Online] Retrieved June, 10, 2018 from https://www.thehindu.com/ news/national/other-states/two-men-lynched-on-suspicion-of-being-child-lifters-in-assam/ article24122413.ece 
Latour, B. (2014). Reassembling the Social. An Introduction to Actor-Network-Theory (translated by Irina Polonskaya), Journal of Economic Sociology, 14(2), 73-87. doi: 10.17323/1726-3247-20132-73-87.

Lovink, G. (2017). Overcoming Internet Disillusionment: On the Principles of Meme Design, E-flux Journal, 83. Retrieved from http://www.e-flux.com/journal/83/141287/overcoming-internetdisillusionment-on-the-principles-of-meme-design/

Milner, R. M. (2012). The World Made Meme: Discourse and Identity in Participatory Media. University of Kansas.

Mitra, A. (1993). Introduction and History of Doordarshan. In Television and Popular Culture in India: A Study of the Mahabharata (pp. 11-42). New Delhi: Sage Publications.

Pesce, S. \& Noto, P. (2016). The Politics of Ephemeral Digital Media: Permanence and Obsolescence in Paratexts. In The Politics of Ephemeral Digital Media (pp. 11-20). Routledge.

Poe, N. (2005). Big contradictions in the evolution theory. [Online] Retrieved September, 19, 2018 from https://web.archive.org/web/20170114124412/http://www.christianforums.com/threads/ big-contradictions-in-the-evolution-theory.1962980/page-3\#post-17606580

PTI. (2017). Assam Chief Minister Sarbananda Sonowal directs stern action against social media misuse. [Online] Retrieved September, 10, 2018 from https://www.firstpost.com/ india/assam-chief-minister-sarbananda-sonowal-directs-stern-action-against-socialmedia-misuse-3459116.html

Raina, P. (2019). New Media and Indian Elections 2019. The Indian Express \& Jindal School of Journalism and Communication's (JSJC) panel discussion, India International Centre, New Delhi delivered March 29, 2019.

Roy, D. D. (2017). NDTV. [Online] Retrieved August, 5, 2017 from https://www.ndtv.com/india-news/ assam-legislator-aminul-islam-suspended-for-broadcasting-speech-on-facebook-live- 1656488

Saikia, A. (2017). Scroll.in. [Online] Retrieved May, 25, 2017 from https://scroll.in/article/831852/ the-fatwa-against-assam-singer-nahid-afreen-that-never-was

Shifman, L. (2014). Memes in Digital Culture. (The MIT Press Essential Knowledge series) Cambridge: MIT Press.

Simondon, G. (1980). On the Mode of Existence of Technical Objects (English Tr.). Ontario: University of Western Ontario.

Sismondo, S. (2018). Post-Truth, Social Studies of Science, 47(1), 3-6. doi: $10.1177 / 0306312717692076$.

Special Correspondent. (2017). Jamshedpur simmers after seven brutal lynchings. [Online] Retrieved September, 16, 2017 from https://www.thehindu.com/news/national/other-states/police-firein-air-as-protests-intensify-against-jharkhand-lynchings/article18518986.ece

Stark, D. \& Castells, M. (1997). The Rise of the Network Society, Contemporary Sociology. Wiley Blackwell. doi: 10.2307/2654643.

The Asian Age. (2017). Assam lawmaker's 'sex tape' goes viral on social media. [Online] Retrieved August, 12, 2017 from https://www.asianage.com/india/politics/190217/assam-lawmakerssex-tape-goes-viral-on-social-media.html

Tripathi, V. (2017). Youth violence and social media, Journal of Social Sciences, 52(1-3), 1-7. doi: 10.1080/09718923.2017.1352614.

Van Zoonen, L. (2006). The personal, the political and the popular: A woman's guide to celebrity politics, European Journal of Cultural Studies, 9(3), 287-301. doi: 10.1177/1367549406066074. 